\title{
Biodegradation of heavy oily sludge by a two-step inoculation composting process using synergistic effect of indigenous isolated bacteria
}

\author{
Maryam Parhamfar ${ }^{\mathrm{a}}$, Hamid Abtahi ${ }^{\mathrm{a}}$, Kazem Godini ${ }^{\mathrm{b}}$, Reza Saeedi ${ }^{\mathrm{c}, \mathrm{d}}$, Majid Sartaj ${ }^{\text {, José }}$ \\ Villaseñor $^{\mathrm{f}}$, Frederic Coulon ${ }^{\mathrm{g}}$, Vinod Kumar ${ }^{\mathrm{g}}$, Tayebeh Soltanighias ${ }^{\mathrm{h}}$, Ehsanollah Ghaznavi- \\ $\operatorname{Rad}^{\mathrm{i}}$, Ali Koolivand ${ }^{\mathrm{j} *}$
}

a Molecular and Medicine Research Center, Arak University of Medical Sciences, Arak, Iran

b Department of Environmental Health Engineering, Faculty of Health, Hamedan University of Medical Sciences, Hamedan, Iran

c Workplace Health Promotion Research Center, Shahid Beheshti University of Medical Sciences, Tehran, Iran

d Department of Health, Safety and Environment (HSE), School of Public Health and Safety, Shahid Beheshti University of Medical Sciences,

Tehran, Iran

e University of Ottawa, Department of Civil Engineering, 161 Louis Pasteur, Ottawa, Ontario K1N 6N5, Canada

f Department of Chemical Engineering, Institute of Chemical\&Environmental Technologies, University of Castilla-La Mancha, Campus

Universitario S/n,13071, Ciudad Real, Spain

g School of Water, Energy and Environment, Cranfield University, Cranfield, United Kingdom

h National Center for Microbial Resource, National Center for Cell Science, Pune, Maharashtra, India

i Molecular Research Center, Faculty of Medicine, Arak University of Medical Sciences, Arak, Iran

j Department of Environmental Health Engineering, Faculty of Health, Arak University of Medical Sciences, Arak, Iran

*Corresponding Author: Ali Koolivand, Email address: alikoulivand@arakmu.ac.ir

\section{Conflict of interest}

The authors declare that they have no conflict of interest.

\section{Acknowledgements}

Authors would like to acknowledge Arak University of Medical Sciences for supporting and funding this research [Grant Number 2819]. The authors are also thankful to Mr. Vahid Koolivand for preparing oily sludge sample from Shazand oil refinery plant.

\section{Abbreviations list ${ }^{1}$}

\footnotetext{
${ }^{1}$ BATH: bacterial adhesion to hydrocarbon, BH: Bushnell-Hus, FP: first phase, FC: finished compost, MBM: mineral-based medium, OC: organic carbon, OD: optical density, HOS: heavy oily sludge, SP: second phase, TPH: total petroleum hydrocarbons
} 


\section{Highlights}

- $\quad$ The strains KA3 and KA4 were isolated from the heavy oily sludge.

- $\quad$ The strains were capable of degrading crude oil in the mineral-based medium.

- The two isolated strains exhibited the synergistic effect in oil biodegradation.

- $\quad$ About $90 \%$ of total petroleum hydrocarbons were removed in the composting system.

- $\quad$ Successful scaling-up was achieved from mineral-based medium to composting process. 


\begin{abstract}
The impact of two-step inoculation of indigenous strains and their synergistic effect in the scaling-up of petroleum hydrocarbons biodegradation from a mineral-based medium (MBM) to a two-phase composting process were investigated. After isolating the strains KA3 and KA4 from heavy oily sludge (HOS), their emulsification index $\left(\mathrm{E}_{24}\right)$, bacterial adhesion to hydrocarbon (BATH), and oil degradation efficiency were evaluated in the MBM. Then, they were inoculated twice into the composting bioreactors lasted for the primary 8 weeks as the first phase (FP) and subsequent 8 weeks as the second phase (SP). The results indicated that the consortium of the two strains degraded $16-61 \%$ of crude oil (1-5\% concentration) in the MBM. In the composting reactors, removals of $20 \mathrm{~g} \mathrm{~kg}^{-1}$ initial concentration of total petroleum hydrocarbons (TPH) were found to be $63.95,61.00$, and $89.35 \%$ for the strains KA3, KA4, and their consortium, respectively. The computed biodegradation constants indicated the synergistic effect of the two strains and the effectiveness of the second-step inoculation. The study demonstrated the successful scaling-up of HOS biodegradation from MBM to the two-phase composting process through two-step inoculation of the isolated strains.
\end{abstract}

Key words: Biodegradation scale-up; Heavy oily sludge; Two-step inoculation; Composting process; Synergistic effect 


\section{Introduction}

Population growth, rapid industrialization and urbanization have increased the world consumption of energy. Despite the continuing rapid growth in renewable energy, crude oil is still the most important strategic source of material and energy and its total production reached 4474 million tonnes in 2018, which shows an increase of $11.9 \%$ compared with 2008 [1]. Processing crude oil in petroleum refinery industries annually produces huge quantities of heavy oily sludge (HOS) [2, 3]. It has been recognized that HOS contains various amounts of petroleum hydrocarbons, water, and heavy metals. Improper disposal of oily sludge can lead to serious environmental and health issues. Hence, there is a need for effective technologies to treat this type of industrial waste before disposal $[4,5]$. Until now, multiple physical and chemical methods have been used as treatment strategies for decontamination of petroleum compounds. However, most of these approaches are not economically and/or ecologically viable. As an alternative, bioremediation technologies such as composting process has shown to be an environmentally sound and cost-effective method to treat petroleum compounds $[6,7]$.

In bioremediation, easily biodegradable compounds are rapidly decomposed and then the rate of biodegradation decreases. This reduction is due to both the persistent nature of the residual hydrocarbons and the limitation in the metabolic activities of microbial population $[8,9]$. Bioremediation of oily sludge is also limited due to the scarcity of native specialized microbes needed for degrading various fractions of petroleum hydrocarbons. In order to overcome these limitations and to promote bioremediation performance, a two-phase composting process and microbial inoculation can be used [10-12]. However, no single microbial species has the ability to metabolize all classes of compounds typically found in crude oil. A consortium composed of many different species is thus required to take advantage of their synergistic interactions [13, 
14]. However, the antagonistic effects such as competition for carbon sources may also influence the growth of bacterial species and thereby decrease the process efficacy, especially in a fullscale bioremediation process. Thus, oily sludge decomposition during bioremediation processes can be complicated by not only biological factors, but also physicochemical parameters [15]. Thion et al. [16] observed antagonistic interactions between the mixed culture of fungus and bacterium in bioremediation of contaminated soils. Hence, one of the most important problems of petroleum hydrocarbons biodegradation has been the lack of effective scale-up of mineralbased medium (MBM) results to full-scale bioremediation methods [17]. For this reason, the appropriate combination of native bacterial species and investigation of their metabolic characteristics and interactions should be performed to optimize and scale-up MBM experiments to full-scale bioremediation processes $[18,19]$.

To the best of our knowledge, scaling-up of HOS bioremediation from MBM to a two-phase composting system through two-step inoculation of isolated indigenous strains has not been reported before. The main purpose of the present study was to the scaling-up of HOS biodegradation from MBM to a two-phase composting method. The study also investigated the synergistic effects of the isolated strains and the impact of two-step inoculation on the composting process. The composting system used in the current research consisted of the first phase (FP), lasted for 8 weeks, followed by the second phase (SP), also lasted for 8 weeks.

\section{Materials and methods}

\subsection{Isolation of oil-degrading bacteria}

HOS was obtained from Shazand oil refinery plant, Iran. The bacterial strains of HOS samples were determined using the serial dilution method. After adding cycloheximide (to 
prevent the growth of fungi) and blending HOS (5 g) with Bushnell-Haas (BH) medium (100 ml) at $160 \mathrm{rpm}$ and incubating at $30{ }^{\circ} \mathrm{C}$ for 7 days, $5 \mathrm{ml}$ of the medium was again mixed with $\mathrm{BH}$ (100 ml) containing $1 \%$ concentration of crude oil as a sole carbon source. The abovementioned method was repeated three times to assure that only the bacteria are responsible for the medium turbidity. Then, the medium (100 $\mu \mathrm{l})$ was spread onto the Muller-Hinton agar and then incubated for $48 \mathrm{~h}$. The formed colonies were again transferred to the surface of Muller-Hinton agar. Each isolated bacterium was mixed with $\mathrm{BH}$ consisting of $1 \%$ concentration of crude oil, and then incubated for 7 days to verify the colonies capabilities in oil degradation. Cell growth was monitored by measuring cell turbidity determined as optical density at $600 \mathrm{~nm}\left(\mathrm{OD}_{600 \mathrm{~nm}}\right)$ in the $\mathrm{MBM}$ or $\mathrm{BH}$ medium. Six strains showing the highest $\mathrm{OD}_{600 \mathrm{~nm}}$ and growth in the presence of crude oil were selected. These 6 strains were also exposed to the concentrations of 1, 2, 3, 4, and $5 \%$ of crude oil. Finally, the two fastest-growing bacterial strains exhibiting high efficacy of oil degradation were selected for further tests and application in the composting experiments.

\subsection{Identification of the isolated bacteria}

The isolates were investigated in terms of various characteristics such as morphology, motility, gram stain test, and biochemical tests. Confirmation of the isolates was conducted by the PCR and Bio-Rad Thermal Cycler based on the procedures reported in a previous work [20]. Electrophoresis of the DNA was performed by agarose gel $(0.8 \%)$ in Tris-Borate-EDTA (TBE) buffer. The PCR product was sequenced by Bioneer Co., Korea mediated by Pishgam Co., Iran. The sequences were analyzed and aligned by Chromas software and ClustalW program. By using BLAST tools, the sequences were compared with NCBI database. CLUSTAL X 2.0 software was applied to include top hit sequences in alignment analysis. Phylogenetic tree was constructed by MEGA software v $7.0[21,22]$. 


\subsection{Determination of emulsification index $\left(E_{24}\right)$}

The $\mathrm{E}_{24}(\%)$ was measured according to the procedure described previously [23, 24]. Briefly, the isolated strains were added to Nutrient Broth and incubated at $30{ }^{\circ} \mathrm{C}$ for $48 \mathrm{~h}$. Then, a mixture of the free cell supernatant and oils were vortexed vigorously for $2 \mathrm{~min}$. After keeping the sample at room temperature for $24 \mathrm{~h}$, the $\mathrm{E}_{24}$ was determined as follows:

$$
E_{24}(\%)=(\text { Height of the emulsified layer/total height of liquid column }) \times 100
$$

\subsection{Determination of bacterial adhesion to hydrocarbon (BATH)}

BATH was determined through the method described by [25] with slight modifications. Briefly, the strains were transferred to Nutrient Agar and incubated at $30{ }^{\circ} \mathrm{C}$ for $24 \mathrm{~h}$. After adding one colony of the strains to a buffer solution, the primary $\mathrm{OD}\left(\mathrm{OD}_{1}\right)$ was determined. Then, $200 \mu \mathrm{l}$ of Hexadecane was added and the mixture was shaken well for $2 \mathrm{~min}$. The hydrocarbon was separated through maintaining at room temperature for $30 \mathrm{~min}$. The BATH was calculated through measuring the secondary $\mathrm{OD}\left(\mathrm{OD}_{2}\right)$ of the aqueous phase as follows:

$$
\operatorname{BATH}(\%)=\left[\left(O D_{1}-O D_{2}\right) / O D_{1}\right] \times 100
$$

\subsection{Crude oil biodegradation in $M B M$}

Before inoculation of the isolated strains in the composting reactors, their capabilities in crude oil biodegradation were investigated in the MBM. Multiple concentrations of crude oil including $1,2,3,4$, and $5 \% \mathrm{v} \mathrm{v}^{-1}$ were used in the 500-ml Erlenmeyer flasks. The process was conducted at neutral $\mathrm{pH}$ and a temperature of $30^{\circ} \mathrm{C}$. After shaking at $120 \mathrm{rpm}$ throughout a 7-day period, oil degradation was calculated. The rates of Total petroleum hydrocarbons (TPH) decrease in MBM were determined as the TPH removal against the control experiments. The control experiments 
were performed under the same conditions without any inoculation. The oil concentration showing the highest biodegradation was selected to be used in the composting bioreactors.

In order to study the influence of $\mathrm{pH}$ on crude oil biodegradation, tests were performed at $\mathrm{pH}$ values of $5,6,7,8$, and 9 . The isolated strains and $1 \%$ concentration of crude oil were blended with $\mathrm{BH}$ and incubated for 7 days and then the $\mathrm{OD}$ and crude oil reduction were calculated. $\mathrm{HCl}$ and $\mathrm{NaOH}$ were used for $\mathrm{pH}$ adjustment of the medium.

\subsection{HOS biodegradation in the composting bioreactors}

Five cylindrical bioreactors were operated for a period of 16 weeks. In the composting reactors, the sterile finished compost (FC) was blended with sterile HOS in the mixing ratio (the weight of FC divided to the weight of HOS) of 12.2:1. The FC purchased from a local market in Arak, Iran, had been prepared from foodwaste and green waste. Naturally, it did not contain some impurities and components such as plastic and glass. The physico-chemical properties of the HOS and FC are presented in the Table S1 (supplementary material). This mixing ratio was selected to reach an initial TPH concentration of $20 \mathrm{~g} \mathrm{~kg}^{-1}$ based on the results of the oil biodegradation in MBM. The composting experiments $\mathrm{A}_{1}, \mathrm{~A}_{2}$, and $\mathrm{A}_{3}$ contained the strains $\mathrm{KA} 3$, $\mathrm{KA} 4$, and their consortium, respectively. At the initiation of the process, each reactor was provided with the $0.5 \mathrm{McFarland}$ of the isolates $\left(5 \% \mathrm{v} \mathrm{v}^{-1}\right)$. At the end of week $8(\mathrm{FP})$, the bacterial inoculation was repeated. For reactor $\mathrm{A}_{4}$, inoculation of the two strains consortium was only performed at the beginning of the process. Comparing the performance of the reactor $\mathrm{A}_{4}$ with $\mathrm{A}_{3}$ would allow to investigate the effect of the once and twice inoculation steps on TPH removal. The reactor $\mathrm{A}_{5}$ was operated as control without any bacterial inoculation to ascertain that it did not have any active microorganisms capable of degrading hydrocarbons. According to the previous papers $[26,27]$, the ratio of $\mathrm{C} / \mathrm{N} / \mathrm{P}$ in the composting bioreactors were adjusted at 
$100 / 5 / 1$ through the addition of $\mathrm{NH}_{4} \mathrm{Cl}$ and $\mathrm{KH}_{2} \mathrm{PO}_{4}$. Aerobic conditions in the reactors were supplied by means of oil-free pumps (HAILEA Model ACO 5505) at the rate of $11 \mathrm{~min}^{-1} \mathrm{~kg}^{-1}$ [28]. The moisture level of the process was kept constant at 50-55\% over the whole composting time.

\subsection{Analytical methods}

The organic carbon (OC) and TPH were determined bi-weekly over the process time. The value of $\mathrm{pH}$ was measured by means of a $\mathrm{pH}$ meter (JENWAY model 3510) according to TMECC [29]. The OC was quantified on the basis of loss-on-ignition method described by TMECC [29]. The TPH was extracted with n-pentane and then quantified by means of a gas chromatograph (Shimadzu, Japan) based on TNRCC [30]. The operating conditions of the gas chromatograph have been described in a previous work [31]. All tests were repeated in triplicate.

\subsection{Kinetic study}

Kinetic study of microbial degradation was also performed to better understand the TPH removal rates during the composting process. Biodegradation of petroleum hydrocarbons was explained by the first and second-order kinetics depicted by the following equations:

$$
\begin{aligned}
& C_{t}=C_{i} e^{-k t} \\
& t_{1 / 2}=\ln 2 / k_{1}=0.693 / k_{1} \\
& 1 / C_{t}=k_{2} t+\left(1 / C_{t}\right) \\
& t_{1 / 2}=1 / k_{2} C_{i}
\end{aligned}
$$

Where $\mathrm{C}_{\mathrm{i}}$ is the initial concentration of TPH $\left(\mathrm{g} \mathrm{kg}^{-1}\right), \mathrm{C}_{\mathrm{t}}$ is TPH concentration $\left(\mathrm{g} \mathrm{kg}^{-1}\right)$ at time $\mathrm{t}, \mathrm{k}_{1}\left(\mathrm{~d}^{-1}\right)$ and $\mathrm{k}_{2}\left(\mathrm{~g} \mathrm{~kg}^{-1} \mathrm{~d}^{-1}\right)$ are biodegradation rate for the first-and second-order kinetics, 
respectively. $t_{1 / 2}$ is the time (d) needed for removing half of the initial level of TPH. The biodegradation rate of TPH was calculated as follows:

TPH biodegradation rate $=\left[\left(\mathrm{TPH}_{1}-\mathrm{TPH}_{2}\right) / \mathrm{TPH} \mathrm{H}_{1}\right] \times 100$

where $\mathrm{TPH}_{1}$ and $\mathrm{TPH}_{2}$ are the amount of $\mathrm{TPH}$ before and after treatment, respectively.

\subsection{Statistical analysis}

One-way ANOVA test (SPSS software) was used to compare the differences (P value $\leq 0.05$ ) between the composting reactors. Regression analysis (Microsoft Excel software) was also applied to determine the possible correlations between the variables.

\subsection{Nucleotide sequence accession numbers}

The nucleotide sequences from this study were deposited in NCBI GenBank under the accession numbers of MK127545 and MK127546, respectively, for Enterobacter hormaechei strain KA3 and Staphylococcus equorum strain KA4.

\section{Results and discussion}

\subsection{Taxonomic and metabolic characterization of the isolated bacteria}

Taxonomic characteristics of the strains were determined by $16 \mathrm{~S}$ rRNA gene sequence analysis. The phylogenetic analysis (Fig. 1) and NCBI Genbank database similarity search demonstrated that the bacteria are Enterobacter hormaechei strain KA3 and Staphylococcus equorum strain KA4. The results of the biochemical tests conducted on the strains have been provided in Table S2 (supplementary material). Table S3 (supplementary material) also presents the metabolic ability of the isolates to grow in the MBM containing $1 \%$ of crude oil. As can be 
inferred, there is a lag in effective bacterial growth during the first 2 days of the incubation period. Then, the biomass was rapidly generated until the day 7-10. From the day 10 onward, the bacterial growth and biomass production started to decrease. Thus, the isolates reached to the logarithmic phase in a period of about 7-10 days. This period was selected as the time of incubation for all the tests performed in the MBM. It can be inferred that both the two individual isolates and their consortium can grow well in the presence of crude oil.

Fig. 1

\subsection{MBM experiments}

\subsubsection{Effect of pH on crude oil biodegradation}

The effect of $\mathrm{pH}$, as a crucial parameter affecting the bacterial metabolism and petroleum hydrocarbons solubility, on the bacterial growth and decomposition of crude oil (1\% concentration) was examined. As can be seen from Table 1, the strains exhibited the highest growth and oil biodegradation at the $\mathrm{pH}$ value of 7 . At this $\mathrm{pH}, 48.85$ and $46.35 \%$ of TPH was removed by the strains KA3 and KA4 during 7 days. At the pHs of 6 and 8, the crude oil degradation decreased slightly and reached to the range of 38.56-41.93\%. However, the biodegradation reduced sharply at the $\mathrm{pH}$ values of 5 and 9 . These findings are in line with other studies $[32,33]$ reporting that the oil degrading bacteria prefer to grow at neutral $\mathrm{pH}$ for TPH removal. The consortium of the two strains also presented the best efficacy and growth in the $\mathrm{pH}$ range of 6-8. For this reason, the composting bioreactors were operated at the neutral condition.

Table 1

\subsubsection{Effect of initial concentration of crude oil}


The effect of initial oil concentrations (1-5\%) on the mineralization of petroleum hydrocarbons was examined in this work. The results (Table 2) showed that the strains were more effective to degrade 1-3\% concentrations of crude oil as the removal percentage dropped significantly at initial oil concentrations of 4 and 5\%. Less effective degradation at these high levels of oil could be due to the bacterial metabolic characteristics and crude oil toxicity. Moreover, high concentration of crude oil can block the aeration, which also affects the bacterial growth [34]. The highest biodegradation occurred at a crude oil concentration of $2 \%$ as after 7 days, 53.94 and $50.68 \%$ of crude oil was degraded, respectively, by the strains KA3 and KA4. The capacity of the isolates for TPH removal was not high at a very low level (1\%) of crude oil. When the carbon source is too low to promote microbial growth, extremely low amount of crude oil would limit TPH removal [3]. Thus, the crude oil amount of $2 \%$ was found to be the optimum initial concentration for the isolates to effectively degrade petroleum hydrocarbons. This optimal concentration was the basis for adjusting the mixing ratios of HOS to FC in the composting setups.

Table 2

\subsubsection{Synergistic effect of the strains}

As can be seen from Tables 1 and 2, the oil degradation by the bacterial consortium was higher than that of the individual strains. Hence, these two strains presented the synergistic effect for TPH biodegradation when they are used in the mixed culture. Several authors $[18,35,36]$ already reported that pure single strains were not able to degrade crude oil effectively compared to their consortium. The positive effects of bacterial consortium compared to individual strains will be deeply discussed in section 3.3.1. $\mathrm{E}_{24}$ was calculated to investigate the ability of the strain in biosurfactant production. The value of BATH was also measured to determine the affinity of 
the strains to the petroleum hydrocarbons. The isolates KA3, KA4, and their consortium showed emulsification index of 13,10 , and $18 \%$, respectively. The corresponding values for BATH were found to be $8.62,16.10$, and $21.10 \%$, respectively. These values also verified the better performance of the consortium as compared to each strain.

\subsubsection{Relation between crude oil degradation and cell growth}

Growth of the individual strains and their consortium in BH medium was also determined (Tables S2, 1, and 2) through measuring the biomass production $\left(\mathrm{OD}_{600 \mathrm{~nm}}\right)$. The crude oil concentration decreased in response to increased cell numbers, indicating that the isolated bacteria can utilize crude oil as a sole source of carbon. Regression analysis presented in Fig. 2, also indicated that the oil biodegradation was in direct correlation with biomass formation of the selected strains. These results of the biomass production demonstrated the ability of the isolates to consume petroleum hydrocarbons as a carbon source. The higher optical density observed in the case of the bacterial consortium showed more effective growth of the consortium as compared to the individual strains.

Fig. 2

\subsection{Scaling-up of HOS biodegradation from MBM to composting process}

\subsubsection{TPH removal}

Determination of the actual role of microbial community for oil degradation in the aqueous phase is not easy since a large fraction of viscous and sticky oil may attach to the surface of flask instead of dispersing in the liquid medium. Hence, it is of vital importance to evaluate the potential of the isolates in biodegradation of petroleum pollutants in a real bioremediation conditions such as composting process. For this reason, we simulated the TPH removal in the 
composting bioreactors based on results obtained from the MBM. Accordingly, the HOS containing $255.05 \mathrm{~g} \mathrm{~kg}^{-1}$ of TPH concentration was blended with FC in the mixing ratio of 12.23:1 to reach an initial concentration of $20 \mathrm{~g} \mathrm{~kg}^{-1}$. The initial TPH concentration is of great importance since the proper adjustment of the mixing ratio greatly affects TPH removal $[37,38]$.

Fig. 3a indicates the trend of TPH decomposition in the composting treatments. The reduction rates of TPH in the reactors $A_{1}, A_{2}, A_{3}$, and $A_{4}$ were 63.95, 61.00, 89.35\%, and 76.20, respectively during 16 weeks. Thus, the biodegradation capacities of the two strains were nearly similar. However, the percentage of TPH degradation significantly increased when their consortium was inoculated to the composting reactors. Hence, application of the two combined isolates resulted in their synergistic effect in terms of TPH removal. As crude oil consists of different hydrocarbons, and each strain can metabolize only a limited range of materials, bioremediation of oily sludge requires a microbial consortium to degrade petroleum hydrocarbons more effectively. A collaboration and synergistic effect between different bacteria makes them act better than a single strain. In recent years, combination of microbial strains for enhancing biodegradation of various types of pollutants has attracted much attention $[13,14]$.

The results of the present study showed that TPH removal by the consortium were 25.40 and $28.35 \%$ higher than the individual cultures of KA3 and KA4, respectively. Kamyabi et al. [13] also reported that an additional $20 \%$ of pyrene removal was achieved by combined cultures in comparison to individual cultures. Other studies have also described the higher ability of consortium to degrade petroleum pollutants $[18,39]$. The negligible TPH removal $(3.8 \%)$ observed in the control reactor $\left(\mathrm{A}_{5}\right)$ indicated that the bacterial populations were responsible for hydrocarbon degradation in the reactors $\mathrm{A}_{1}-\mathrm{A}_{4}$.

Fig. 3 


\subsubsection{Effect of two-step inoculation on TPH reduction}

In the case of one-step inoculation (the reactor $\mathrm{A}_{4}$ ), high degradation of petroleum compounds and thereby TPH removal were initiated until the end of week 8 , and then, the biodegradation rate lowered to the end of the process. It has been reported in previous works $[40,41]$ that the biodegradation of petroleum materials proceeds rapidly in the beginning weeks of the composting process and slows down in the later. This pattern is due to the fact that the type and composition of petroleum hydrocarbons present in crude oil determine their susceptibility to microbial degradation. Accordingly, easily-biodegradable hydrocarbons are consumed first and the remained fractions are resistant to biodegradation $[3,34]$. Naturally, the number or metabolic activity of the oil-degrading bacteria declines. As the bioremediation efficacy is a function of the extent to which microbes are maintained in the system, microbial deficiency limits the effectiveness of the process. Hence, the application of bacterial strain as inoculums is advantageous in cases where there is a lack of appropriate microorganisms or pollutant toxicity $[14,42]$. In this regards, the inoculation of native and specialist bacterial strains is helpful because of their high adaptation abilities to crude oil containing environments [43, 44]. On the other hand, in some cases, the introduced microorganisms are not necessarily adapted to environmental conditions. Therefore, addition of large quantities of biomass can act momentarily as biocatalyst, before vanishing due to the inappropriate conditions [45]. For this reason, a twophase composting, in which the bacterial communities are provided through two-step inoculation, was designed in the current work.

Removal percentages of TPH in various durations of the process were shown in Fig. 3b. In the reactors $A_{1}$ and $A_{2}, 32.50$ and $31.90 \%$ of TPH were removed over the FP. The corresponding values over the SP were 31.45 and $29.10 \%$, respectively. As a result, a suitable efficacy of TPH 
degradation was yielded over both the FP and SP in these two experiments. The higher removal percentage observed at the weeks 10 and 12 (Table 3) supported the positive effect of reinoculation in promoting the process efficacy. These results are in line with other studies reporting the higher efficiency of two-phase composting compared to conventional one-phase system $[12,46]$. It is interesting to note that although easily-biodegradable hydrocarbons were consumed over the FP, petroleum hydrocarbons continued to decompose during the SP, mainly as a result of bacterial reinoculation at a high concentration. The effective role of microbial inoculation in hydrocarbon removal has also been indicated previously [20, 43].

Table 3

The biodegradation rates of TPH in the reactor $\mathrm{A}_{3}$ were 64.05 and $25.30 \%$ over the FP and SP, respectively. Hence, the second-step inoculation did not enhance the process performance during the SP. Comparing the TPH biodegradation in the experiments $\mathrm{A}_{3}$ and $\mathrm{A}_{4}$ is also helpful in terms of the effectiveness of the two-phase composting when the bacterial consortium is used. These two reactors were thoroughly similar in terms of initial TPH concentration and bacterial strains. However, unlike other reactors, $\mathrm{A}_{4}$ was a conventional composting process experiencing a one-step inoculation. Naturally, TPH reductions in these two reactors were similar over the FP of the process duration. The overall removal rate in the $\mathrm{A}_{3}$ was only $13.15 \%$ higher than that $\mathrm{A}_{4}$. This also demonstrated that the application of two-step inoculation of bacterial consortium is not justifiable. Accordingly, the composting process can perform well in the form of conventional one phase when the microbial consortium is used. Thus, the strains combination and the positive synergistic effect would compensate the requirements of periodic inoculations when using individual strains.

\subsubsection{Effect of bulking agent addition on the bioreactors performance}


Since microbes prefer to consume less recalcitrant organic carbons, the presence of easilydecomposable materials can help maintain the bacterial activity in the system. On the other hand, the organic materials used must not be preferred over the target contaminant. Furthermore, the bulking agent should not add at high concentrations in which they act as a sole carbon source [3, 12]. In this point of view, the type and level of bulking agent used in the composting process significantly influence microbial growth.

In order to survey the effect of addition of FC (as a bulking agent) on the TPH degradation, the change of OC and TPH/OC was plotted in Fig. 4. The decrement in the ratio of TPH/OC showed that TPH biodegradation was higher than that of OC. Therefore, the bulking agent added to the composting reactors was not a competing carbon source for petroleum hydrocarbons.

Bulking agents such as FC promote the capacity of the composting mixture in maintaining water contents, which can help the bacterial growth. In addition, they facilitate air diffusion through the composting medium resulting in the higher heat generation and rapid TPH removal [47]. The regression analysis (Fig. 5) indicated linear correlation between the biodegradation of TPH and OC. In the large-scale composting facilities, prediction of TPH removal on the basis of OC consumption can be done using these correlations and computed equations.

Fig. 4

Fig. 5

\subsubsection{Bioremediation kinetic study}

According to the computed values presented in Table 4, TPH removal fitted to the first and second-order model over the FP and SP, respectively. This result is in accordance with other studies reporting that biodegradation of petroleum hydrocarbons proceeds according to the firstand second-order kinetics $[48,49]$. The values of $\mathrm{t}_{1 / 2}$ and $\mathrm{k}_{1}$ for the first-order kinetic over the FP 
were in the range of 5.17-13.59 $\mathrm{d}$ and $0.051-0.134 \mathrm{~d}^{-1}$, respectively. The corresponding values for the second-order kinetic over the SP were respectively, 1.11-5.56 d and 0.009-0.045 $\mathrm{g} \mathrm{kg}^{-1} \mathrm{~d}^{-1}$. All the values in the table demonstrated the better performance of the reactor $\mathrm{A}_{3}$ containing the bacterial consortium compared to the reactors $\mathrm{A}_{1}$ and $\mathrm{A}_{2}$. Moreover, the higher values of $\mathrm{k}_{1}$ and $\mathrm{k}_{2}$ during SP verified the effectiveness of the second inoculation. The values of $\mathrm{k}$ obtained in the present research were different to those computed by Gomez and Sartaj [50]. The reason is the highly dependence of the kinetic values on multiple parameters like the nature of oily sludge, the method of bioremediation, and operational conditions of the system [51, 52].

Table 4

\section{Conclusions}

The impact of two-step inoculation of native strains and their synergistic effect in the scalingup of HOS bioremediation from MBM to the two-phase composting system were studied. The strains were effectively able to remove TPH both in MBM and in composting process. The results revealed the synergistic potential of the consortium of the strains KA3 and KA4 as compared to their individual cultures. The second-step inoculation of each strain alone greatly enhanced TPH removal rate. However, the efficacy of the composting process did not significantly increased as a result of the second-step inoculation of the consortium. This research indicated the successful scaling-up of HOS treatment from MBM to the used composting method through two-step inoculation of the isolated strains. 


\section{References}

1. British Petroleum (BP). Statistical Review of world energy, 68th edition. 2019.

2. S. Srikanth, M. Kumar, S.K. Puri, Bio-electrochemical system (BES) as an innovative approach for sustainable waste management in petroleum industry, Bioresour. Technol. 265 (2018) 506-518.

3. S.J. Varjani, V.N. Upasani, A new look on factors affecting microbial degradation of petroleum hydrocarbon pollutants, Int. Biodeter. Biodegrad. 120 (2017) 71-83.

4. J. Xu, Q. Zhang, D. Li, J. Du, C. Wang, J. Qin, Rapid degradation of long-chain crude oil in soil by indigenous bacteria using fermented food waste supernatant, Waste Manage. 85 (2019) 361-373.

5. R.E.C. Pabón, C.R. de Souza Filho, W.J. de Oliveira, Reflectance and imaging spectroscopy applied to detection of petroleum hydrocarbon pollution in bare soils, Sci. Total Environ. 649 (2019) 1224-1236

6. S.P. Maletić, J.M. Beljin, S.D. Rončević, M.G. Grgić, B.D. Dalmacija, State of the art and future challenges for polycyclic aromatic hydrocarbons is sediments: sources, fate, bioavailability and remediation techniques, J. Hazard. Mater. 365 (2019) 467-482.

7. Y. Zhao, Y. Bai, Q. Guo, Z. Li, M. Qi, X. Ma, H. Wang, D. Kong, A. Wang, B. Liang, Bioremediation of contaminated urban river sediment with methanol stimulation: Metabolic processes accompanied with microbial community changes, Sci. Total Environ. 653 (2019) 649-657.

8. M. Chen, P. Xu, G. Zeng, C. Yang, D. Huang, J. Zhang, Bioremediation of soils contaminated with polycyclic aromatic hydrocarbons, petroleum, pesticides, chlorophenols and heavy 
metals by composting: Applications, microbes and future research needs, Biotechnol. Adv. 33 (6) (2015) 745-755.

9. M.W. Lim, E. Von Lau, P.E. Poh, A comprehensive guide of remediation technologies for oil contaminated soil: Present works and future directions, Mar. Pollut. Bullet. 109 (1) (2016) $14-45$.

10. Q. Liu, Q. Li, N. Wang, D. Liu, L. Zan, L. Chang, X. Gou, P. Wang, Bioremediation of petroleum-contaminated soil using aged refuse from landfills, Waste Manage. 77 (2018) $576-585$.

11. F. Gomez, M. Sartaj, Optimization of field scale biopiles for bioremediation of petroleum hydrocarbon contaminated soil at low temperature conditions by response surface methodology (RSM), Int. Biodeter. Biodegrad. 89 (2014) 103-109.

12. L. Zhang, X. Sun, Influence of bulking agents on physical, chemical, and microbiological properties during the two-stage composting of green waste, Waste Manage. 48 (2016) 115126.

13. A. Kamyabi, H. Nouri, H. Moghimi, Synergistic Effect of Sarocladium sp. and Cryptococcus sp. Co-Culture on Crude Oil Biodegradation and Biosurfactant Production, Appl. Biochem. Biotechnol. 182 (1) (2017) 324-334.

14. M. Wu, L. Chen, Y. Tian, Y. Ding, W.A. Dick, Degradation of polycyclic aromatic hydrocarbons by microbial consortia enriched from three soils using two different culture media, Environ. Pollut. 178 (2013) 152-158.

15. J. Liang, T. Cheng, Y. Huang, J. Liu, Petroleum degradation by Pseudomonas sp. ZS1 is impeded in the presence of antagonist Alcaligenes sp. CT10, AMB Express 8 (1) (2018) 88. 
16. C. Thion, A. Cébron, T. Beguiristain, C. Leyval, PAH biotransformation and sorption by Fusarium solani and Arthrobacter oxydans isolated from a polluted soil in axenic cultures and mixed co-cultures Int. Biodeter. Biodegrad. 68 (2012) 28-35.

17. L. Mu, Q. Zhou, Y. Zhao, X. Liu, X. Hu, Graphene oxide quantum dots stimulate indigenous bacteria to remove oil contamination, J. Hazard. Mater. 366 (2019) 694-702.

18. Y.M. He, X.G. Duan, Y.S. Liu, Enhanced bioremediation of oily sludge using co-culture of specific bacterial and yeast strains, J. Chem. Technol. Biotechnol. 89 (11) (2014) 17851792.

19. J.A. Siles, R. Margesin, Insights into microbial communities mediating the bioremediation of hydrocarbon-contaminated soil from an Alpine former military site, Appl. Microbiol. Biotechnol. 102 (10) (2018) 4409-4421.

20. J. Sarkar, S.K. Kazy, A. Gupta, A. Dutta, B. Mohapatra, A. Roy, P. Bera, A. Mitra, P. Sar, Biostimulation of indigenous microbial community for bioremediation of petroleum refinery sludge, Front. Microbiol. 7 (2016) 1407.

21. W. Chen, J. Li, X. Sun, J. Min, X. Hu, High efficiency degradation of alkanes and crude oil by a salt-tolerant bacterium Dietzia species CN-3, Int. Biodeter. Biodegrad. 118 (2017) $110-118$.

22. S. Kumar, G. Stecher, K. Tamura, MEGA7: molecular evolutionary genetics analysis version 7.0 for bigger datasets, Molecul. Biol. Evolut. 33 (7) (2016) 1870-1874.

23. Z. Bayat, M. Hassanshahian, M.A. Hesni, Study the symbiotic crude oil-degrading bacteria in the mussel Mactra stultorum collected from the Persian Gulf, Mar. Pollut. Bullet. 105 (1) (2016) 120-124. 
24. K. Patowary, R. Patowary, M.C. Kalita, S. Deka, Characterization of biosurfactant produced during degradation of hydrocarbons using crude oil as sole source of carbon, Front. Microbiol. 8 (6) (2017) 279.

25. X. Chen, D. Song, J. Xu, E. Li, G. Sun, M. Xu, Role and mechanism of cell-surface hydrophobicity in the adaptation of Sphingobium hydrophobicum to electronic-waste contaminated sediment, Appl. Microbiol. Biotechnol. 102 (2018) 2803-2815.

26. A. Koolivand, K. Naddafi, R. Nabizadeh, R. Saeedi, Optimization of combined in-vessel composting process and chemical oxidation for remediation of bottom sludge of crude oil storage tanks, Environ. Technol. 39 (20) (2018) 2597-2603.

27. A. Koolivand, H. Abtahi, M. Parhamfar, M. Didehdar, R. Saeedi, S. Fahimirad, Biodegradation of high concentrations of petroleum compounds by using indigenous bacteria isolated from petroleum hydrocarbons-rich sludge: Effective scale-up from liquid medium to composting process, J. Environ. Manage. 248 (2019) 109228.

28. M. Wu, X. Ye, K. Chen, W. Li, J. Yuan, X. Jiang, Bacterial community shift and hydrocarbon transformation during bioremediation of short-term petroleum-contaminated soil, Environ. Pollut. 223 (2017) 657-664.

29. TMECC. Test methods for the examination of composting and compost. USDA and US Composting Council. 2002.

30. TNRCC. Total petroleum hydrocarbons, method 1005. Texas Natural Resource Conservation Commission. 2001.

31. A. Koolivand, K. Naddafi, R. Nabizadeh, S. Nasseri, A.J. Jafari, M. Yunesian, K. Yaghmaeian, Degradation of petroleum hydrocarbons from bottom sludge of crude oil 
storage tanks using in-vessel composting followed by oxidation with hydrogen peroxide and Fenton, J. Mater. Cycles Waste Manage. 15 (3) (2013) 321-327.

32. C. Muangchinda, A. Rungsihiranrut, P. Prombutara, S. Soonglerdsongpha, O. Pinyakong, 16S metagenomic analysis reveals adaptability of a mixed-PAH-degrading consortium isolated from crude oil-contaminated seawater to changing environmental conditions, J. Hazard. Mater. 357 (2018) 119-127.

33. F. Wang, C. Li, H. Wang, W. Chen, Q. Huang, Characterization of a phenanthrene-degrading microbial consortium enriched from petrochemical contaminated environment, Int. Biodeter. Biodegrad.115 (2016) 286-292.

34. M.K. Awasthi, A. Selvam, M.T. Chan, J.W.C. Wong, Bio-degradation of oily food waste employing thermophilic bacterial strains, Bioresour. Technol. 248 (2018) 141-147.

35. S.J. Varjani, Microbial degradation of petroleum hydrocarbons, Bioresour. Technol. 223 (2017) 277-286.

36. C. Zhang, J. Qi, Y. Cao, Synergistic effect of yeast-bacterial co-culture on bioremediation of oil-contaminated soil, Biorem. J. 18 (2) (2014) 136-146.

37. A. Koolivand, K. Naddafi, R. Nabizadeh, S. Nasseri, A.J. Jafari, M. Yunesian, K. Yaghmaeian, S. Nazmara, Biodegradation of petroleum hydrocarbons of bottom sludge from crude oil storage tanks by in-vessel composting, Toxicol. Environ. Chem. 95 (1) (2013) 101-109.

38. M. Farzadkia, A. Esrafili, M. Gholami, A. Koolivand, Effect of immature and mature compost addition on petroleum contaminated soils composting: kinetics, J. Environ. Health Sci. Eng. (2019) Doi: 10.1007/s40201-019-00400-y. 
39. I. Mnif, S. Mnif, R. Sahnoun, S. Maktouf, Y. Ayedi, S. Ellouze-Chaabouni, D. Ghribi, Biodegradation of diesel oil by a novel microbial consortium: comparison between coinoculation with biosurfactant-producing strain and exogenously added biosurfactants, Environ. Sci. Pollut. Res. 22 (19) (2015) 14852-14861.

40. A. Koolivand, H. Abtahi, K. Godini, R. Saeedi, M.S. Rajaei, M. Parhamfar, Biodegradation of oil tank bottom sludge using a new two-phase composting process: kinetics and effect of different bulking agents, J. Mater. Cycles Waste Manage. 21 (6) (2019) 1280-1290.

41. A. Koolivand, K. Naddafi, R. Nabizadeh, A. Jafari, S. Nasseri, M. Yunesian, K. Yaghmaeian, M. Alimohammadi, Application of hydrogen peroxide and fenton as pre-and post-treatment steps for composting of bottom sludge from crude oil storage tanks, Pet. Sci. Technol. 32 (13) (2014) 1562-1568.

42. M.S. Poorsoleiman, S.A. Hosseini, A. Etminan, H. Abtahi, A. Koolivand, Effect of two-step bioaugmentation of an indigenous bacterial strain isolated from oily waste sludge on petroleum hydrocarbons biodegradation: Scaling-up from a liquid mineral medium to a two-stage composting process, Environ. Technol. Innov. (2019) 100558.

43. A. Roy, A. Dutta, S. Pal, A. Gupta, J. Sarkar, A. Chatterjee, A. Saha, P. Sarkar, P. Sar, S.K. Kazy, Biostimulation and bioaugmentation of native microbial community accelerated bioremediation of oil refinery sludge, Bioresour. Technol. 253 (2018) 22-32.

44. F. Suja, F. Rahim, M.R. Taha, N. Hambali, M.R. Razali, A. Khalid, A. Hamzah, Effects of local microbial bioaugmentation and biostimulation on the bioremediation of total petroleum hydrocarbons (TPH) in crude oil contaminated soil based on laboratory and field observations, Int. Biodeter. Biodegrad. 90 (2014) 115-122. 
45. S. Semrany, L. Favier, H. Djelal, S. Taha, A. Amrane, Bioaugmentation: possible solution in the treatment of bio-refractory organic compounds (Bio-ROCs), Biochem. Eng. J. 69 (2012) 75-86.

46. Y.Y. Long, Y. Fang, C. Zhang, Y. Du, J. Shentu, D.S. Shen, Degradation of polychlorinated biphenyls by sequential anaerobic-aerobic composting, Water Air Soil Pollut. 226 (3) (2015) 1-12.

47. J. Ma, Y. Yang, X. Dai, Y. Chen, H. Deng, H. Zhou, S. Guo, G. Yan, Effects of adding bulking agent, inorganic nutrient and microbial inocula on biopile treatment for oil-field drilling waste, Chemosphere 150 (2016) 17-23.

48. A.S. Nwankwegu, M.U. Orji, C.O. Onwosi, Studies on organic and in-organic biostimulants in bioremediation of diesel-contaminated arable soil, Chemosphere 162 (2016) 148-156.

49. S.Y. Wang, Y.C. Kuo, A. Hong, Y.M. Chang, C.M. Kao, Bioremediation of diesel and lubricant oil-contaminated soils using enhanced landfarming system, Chemosphere 164 (2016) 558-567.

50. F. Gomez, M. Sartaj, Field scale ex-situ bioremediation of petroleum contaminated soil under cold climate conditions, Int. Biodeter. Biodegrad. 85 (2013) 375-382.

51. X.S. He, B.D. Xi, Z.Y. Zhang, R.T. Gao, W.B. Tan, D.Y. Cui, Insight into the evolution, redox, and metal binding properties of dissolved organic matter from municipal solid wastes using two-dimensional correlation spectroscopy, Chemosphere 117 (2014) 701-707.

52. D. Kulikowska, Kinetics of organic matter removal and humification progress during sewage sludge composting, Waste Manage. 49 (2016) 196-203. 
Table 1. Effect of $\mathrm{pH}$ on the efficacy of the isolated strains in biodegradation of $1 \%$ concentrations of crude oil in the MBM after a period of 7 days

\begin{tabular}{lllll}
\hline Parameter & pH & $\begin{array}{l}\text { Strain } \\
\text { KA3 }\end{array}$ & $\begin{array}{l}\text { Strain } \\
\text { KA4 }\end{array}$ & Consortium \\
\hline & 5 & 27.17 & 24.67 & 33.27 \\
Percentage & 6 & 41.93 & 38.56 & 52.78 \\
of crude oil & 7 & 48.85 & 46.35 & 61.09 \\
degradation & 8 & 39.87 & 39.56 & 53.38 \\
& 9 & 35.91 & 32.04 & 45.50 \\
\hline & 5 & 0.75 & 0.68 & 0.86 \\
& 6 & 1.06 & 1.03 & 1.22 \\
& 7 & 1.29 & 1.26 & 1.49 \\
& 8 & 1.09 & 1.07 & 1.13 \\
& 9 & 0.85 & 0.63 & 0.87 \\
\hline
\end{tabular}

Table 2. Efficacy of the isolated strains in biodegradation of various concentrations of crude oil in the MBM after a period of 7 days at an initial $\mathrm{pH}$ of 7

\begin{tabular}{lllll}
\hline Parameter & $\begin{array}{l}\text { Crude oil } \\
\text { concentrations }\end{array}$ & $\begin{array}{l}\text { Strain } \\
\text { KA3 }\end{array}$ & $\begin{array}{l}\text { Strain } \\
\text { KA4 }\end{array}$ & Consortium \\
\hline & $1 \%$ & 48.85 & 46.35 & 57.12 \\
Percentage & $2 \%$ & 53.94 & 50.68 & 61.17 \\
of crude oil & $3 \%$ & 50.06 & 46.12 & 59.87 \\
degradation & $4 \%$ & 20.76 & 14.91 & 32.50 \\
& $5 \%$ & 8.06 & 4.29 & 16.38 \\
\hline & $1 \%$ & 1.29 & 1.26 & 1.49 \\
& $2 \%$ & 1.65 & 1.48 & 1.65 \\
& $3 \%$ & 1.41 & 1.06 & 1.43 \\
& $4 \%$ & 0.61 & 0.31 & 0.88 \\
& $5 \%$ & 0.39 & 0.08 & 0.45 \\
\hline
\end{tabular}


Table 3. Percentage of TPH removal over the process duration

\begin{tabular}{lllll}
\hline \multirow{2}{*}{$\begin{array}{l}\text { Process time } \\
\text { (week) }\end{array}$} & \multicolumn{4}{l}{ Percentage of TPH removal } \\
\cline { 2 - 5 } & $\mathbf{A}_{\mathbf{1}}$ & $\mathbf{A}_{\mathbf{2}}$ & $\mathbf{A}_{\mathbf{3}}$ & $\mathbf{A}_{\mathbf{4}}$ \\
\hline 0 & 0.00 & 0.00 & 0.00 & 0.00 \\
2 & 6.15 & 5.55 & 11.50 & 11.45 \\
4 & 9.65 & 9.75 & 20.80 & 20.55 \\
6 & 10.10 & 11.60 & 20.50 & 20.80 \\
8 & 6.60 & 5.00 & 11.25 & 11.20 \\
10 & 9.15 & 9.30 & 13.70 & 8.25 \\
12 & 13.60 & 13.05 & 7.75 & 2.90 \\
14 & 4.95 & 5.05 & 3.55 & 0.80 \\
16 & 3.75 & 1.70 & 0.30 & 0.25 \\
Total & 63.95 & 61.00 & 89.35 & 76.20 \\
\hline
\end{tabular}

Table 4. Kinetic data of TPH biodegradation in the composting bioreactors over the FP and SP

\begin{tabular}{|c|c|c|c|c|c|c|c|}
\hline \multirow{2}{*}{$\begin{array}{l}\text { Composting } \\
\text { phases }\end{array}$} & \multirow{2}{*}{$\begin{array}{l}\text { Composting } \\
\text { experiments }\end{array}$} & \multicolumn{3}{|c|}{ First-order kinetics } & \multicolumn{3}{|c|}{ Second-order kinetics } \\
\hline & & $k_{1}\left(d^{-1}\right)$ & $t_{1 / 2}(d)$ & $\mathbf{R}^{2}$ & $k_{2}\left(g_{k g}^{-1} d^{-1}\right)$ & $t_{1 / 2}(d)$ & $\mathbf{R}^{2}$ \\
\hline \multirow{3}{*}{ FP } & $A_{1}$ & 0.051 & 13.59 & 0.990 & 0.003 & 16.67 & 0.982 \\
\hline & $\mathrm{A}_{2}$ & 0.051 & 13.59 & 0.980 & 0.003 & 16.67 & 0.974 \\
\hline & $\mathrm{A}_{3}$ & 0.134 & 5.17 & 0.977 & 0.011 & 4.55 & 0.938 \\
\hline \multirow{3}{*}{ SP } & $A_{1}$ & 0.082 & 8.45 & 0.970 & 0.009 & 5.56 & 0.983 \\
\hline & $A_{2}$ & 0.074 & 9.36 & 0.945 & 0.007 & 7.14 & 0.960 \\
\hline & $A_{3}$ & 0.157 & 4.41 & 0.922 & 0.045 & 1.11 & 0.958 \\
\hline
\end{tabular}


Fig. 1. Phylogenetic tree based on 16S rRNA gene sequences of the two bacterial strains isolated from HOS

99 Staphylococcus equorum subsp. equorum|ATCC 43958|AB009939

$75[$ Staphylococcus equorum subsp. linens|RP29|AF527483

38 Isolated strain (Staphylococcus equorum strain KA4)

- Staphylococcus arlettae|ATCC 43957|AB009933

59 [ Staphylococcus cohnii subsp. cohnii|ATCC 29974|D83361

81 Staphylococcus cohnii subsp. urealyticus|ATCC 49330|AB009936

96 Staphylococcus succinus subsp. succinus|AMGD1|AF004220

99 Staphylococcus succinus subsp. casei|SB72|AJ320272

[Staphylococcus caeli|82B|MH431939|98.67

70 89| Staphylococcus saprophyticus subsp. saprophyticus|ATCC 15305|AP008934

89| Staphylococcus edaphicus|P5085|KY315825

64

76 Staphylococcus saprophyticus subsp. bovis|GTC 843|AB233327

[ Staphylococcus haemolyticus|MTCC 3383|LILF01000056

59 Staphylococcus hominis subsp. hominis|DSM 20328|X66101

99

Staphylococcus warneri|ATCC 27836|L37603

- Staphylococcus aureus subsp. aureus|DSM 20231|AMYL01000007

[Staphylococcus epidermidis|ATCC 14990|L37605

${ }_{95}$ Staphylococcus capitis subsp. urealyticus|GTC 727|AB233325

- Staphylococcus intermedius|NCTC 11048|CAIB01000045

99 Staphylococcus chromogenes|ATCC 43764|D83360

- Salmonella enterica subsp. diarizonae|DSM 14847|EU014688|

Kosakonia pseudosacchari|JM387|FXWP01000029

[Enterobacter sichuanensis|WCHEC11597|POVL01000141

74 - Enterobacter asburiae|JCM 6051|BBED01000197

$\mid \begin{aligned} & 47 \\ & 55\end{aligned}$ Isolated strain (Enterobacter hormaechei strain KA3)

71 55. Enterobacter hormaechei subsp. xiangfangensis|LMG 27195|FYBF01000083

76- Enterobacter hormaechei subsp. steigerwaltii|DSM 16691|CP017179|

Enterobacter hormaechei subsp. hoffmannii|EN114|CP017186

Enterobacter hormaechei subsp. hormaechei|ATCC 49162|AFHR01000079

Enterobacter hormaechei subsp. oharae|DSM 16687|CP017180

74 Leclercia adecarboxylata|NBRC 102595|BCNP01000062|

24 Enterobacter ludwigii|EN119|JTLO01000001|97.69|

62 Erwinia aphidicola|DSM 19347|AB273744

[Enterobacter bugandensis|EB247|FYBI01000003|

Enterobacter cancerogenus|ATCC 33241|FYBA01000020

39 [ Enterobacter aerogenes|KCTC 2190|CP002824

22 - Klebsiella oxytoca|JCM 1665|AB004754

_ Citrobacter freundii|DSM 30039|AJ233408

99 Citrobacter werkmanii|NBRC 105721|BBMW01000025 
Fig. 2. Correlation between biomass generation $\left(\mathrm{OD}_{600}\right)$ and oil degradation in the $\mathrm{MBM}$

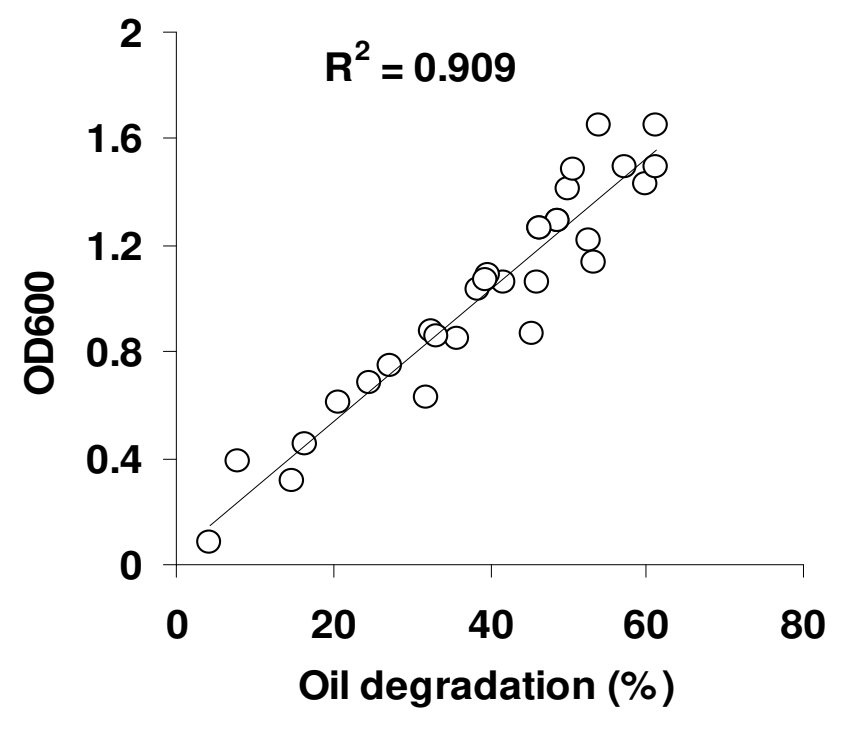


Fig. 3. (a) Residual TPH over the process duration in the composting bioreactors; and (b) percentages of TPH removal over the FP and SP duration in the composting bioreactors
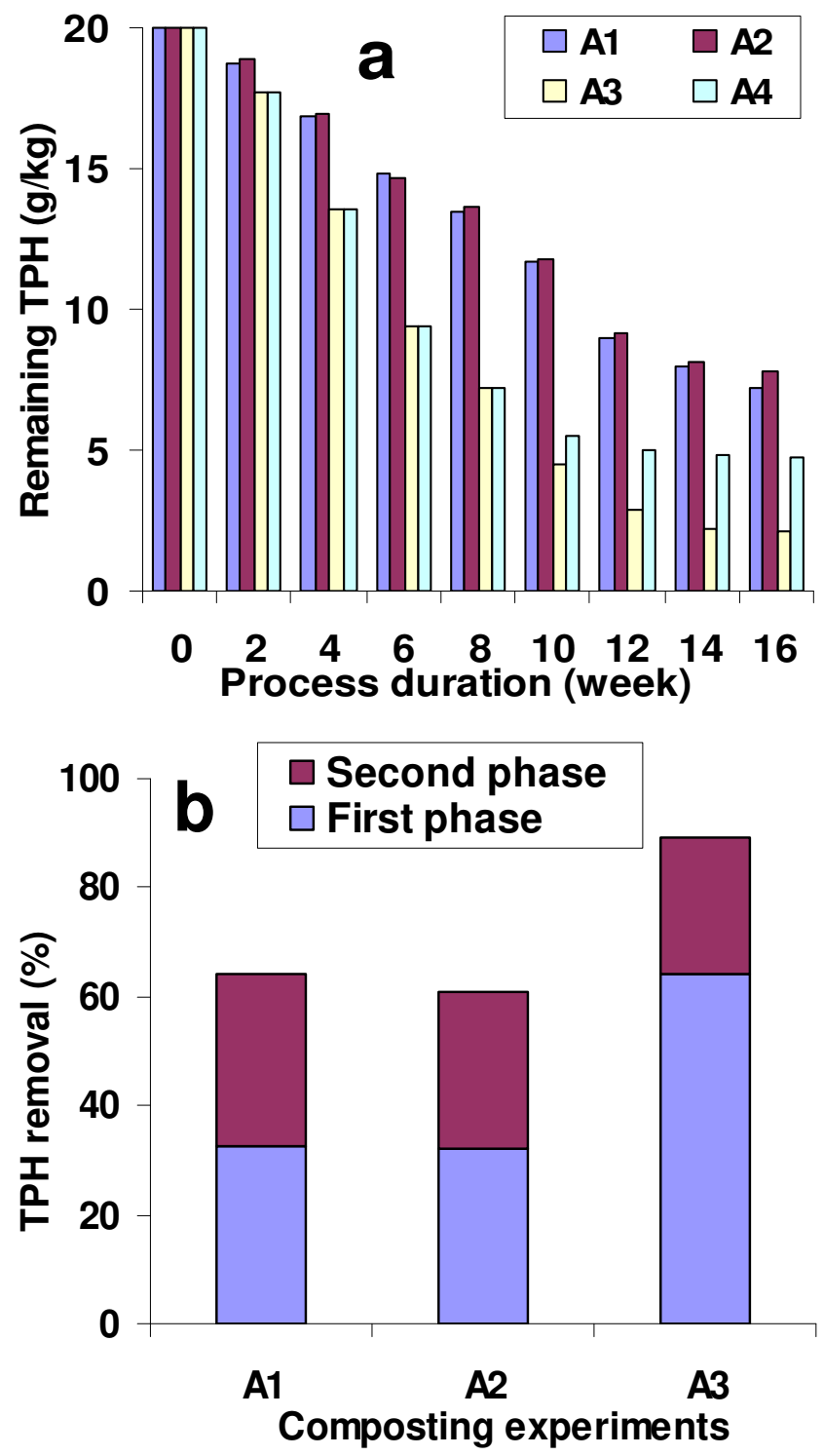
Fig. 4. (a) Trend of OC and (b) TPH/OC changes in the composting bioreactors over the process duration
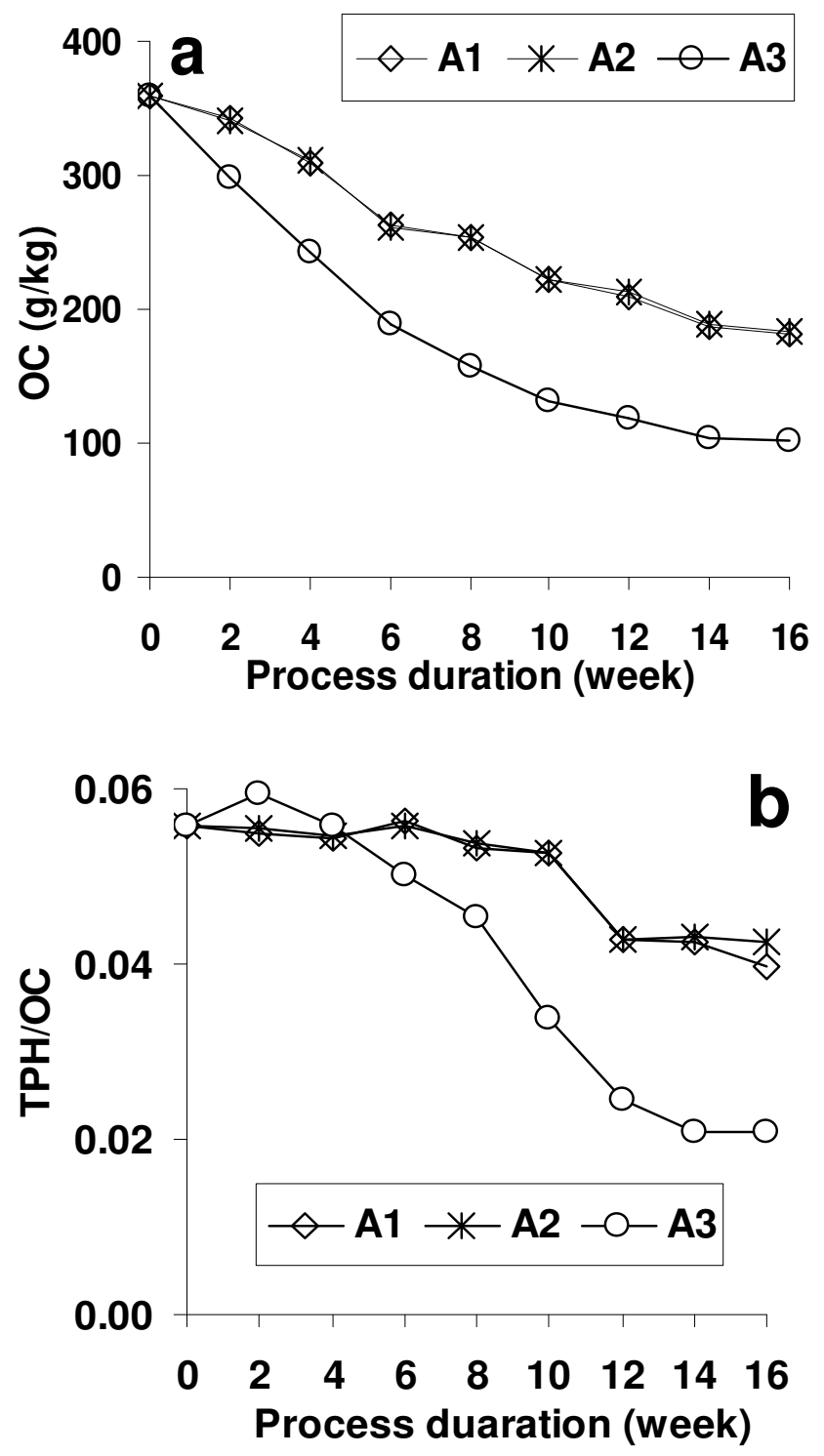
Fig. 5. Regression analysis of OC and TPH correlation in the composting bioreactors over the (a) FP and (b) SP
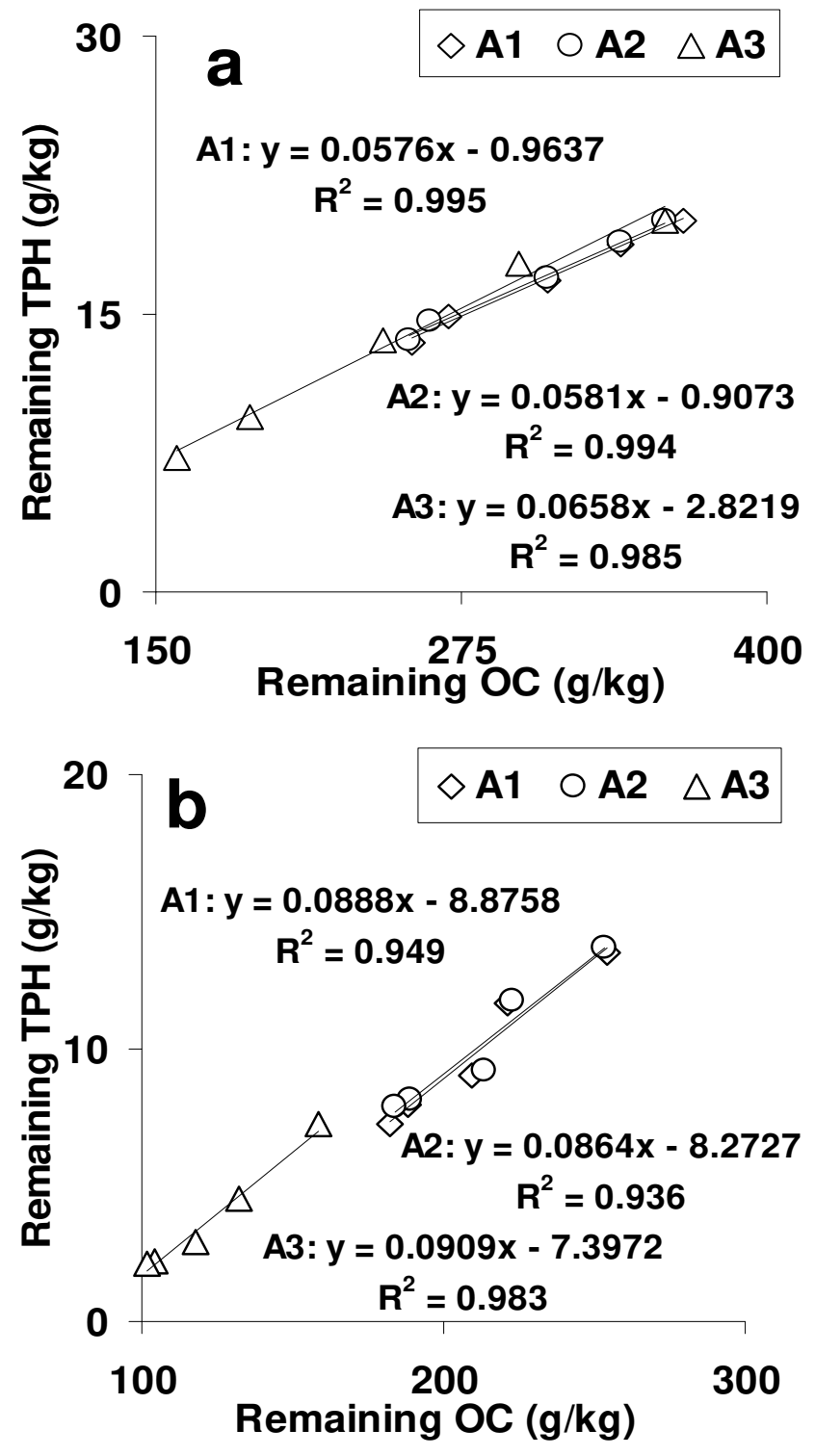